\title{
Acute coronary syndrome: an ideal scenario for direct Absorb implantation?
}

\author{
Javier Suárez de Lezoํㄹ Pedro Martín², Jorge Chavarría ${ }^{1}$ \\ ${ }^{1}$ Reina Sofía Hospital. University of Córdoba, Córdoba, Spain \\ ${ }^{2}$ Doctor Negrín Hospital, University of Las Palmas, Las Palmas, Spain
}

Article Rzeszutko et al., see p. 1434

Implantation of the drug-eluting bioresorbable vascular scaffold (BVS) (Abbott Vascular, Santa Clara, CA, USA) has been shown to be safe [1-7], and it may provide additional advantages compared to metallic stent implantation [1-3]. However, due to the particular features of the platform (strut thickness $-152 \mu \mathrm{m}$, crossing profile $-1.4 \mathrm{~mm}$ ) and the high rate of scaffold thrombosis reported [4, 5], it has been strongly recommended that before the BVS implantation the lesion be prepared through predilation and that systematic postdilation with proper sizing of the device be performed [6].

However, the characteristics of the treated lesions are different, depending on the clinical setting. Our group confirmed the feasibility and safety of direct implantation in favourable lesions [7]: in acute coronary syndromes (ACSs) the rate of success was $88 \%$, and in lesions of stable patients (selected by a previous intravascular ultrasound) the success rate was $84 \%$. In the setting of ACS, when the plaque is soft and the struts are easily embedded, direct implantation should not be an issue. In fact, in the TROFI II trial [8] in patients with ST-segment elevation myocardial infarction, direct implantation was performed in almost half of the lesions, and the healing score at six months was similar to that observed for the Xience stent, with a tendency to be even better. Rzeszutko et al. [9] confirm that direct implantation in this scenario is feasible (91\% success rate), saves procedural and fluoroscopy times, and uses less contrast dye compared with implantation with previous predilation (control group). In addition, direct implantation enables to accomplish correct expansion, as revealed by the greater acute gain compared with the predilation group $(1.89 \pm 0.7 \mathrm{~mm}$ vs. $1.59 \pm 0.7 \mathrm{~mm})$. Another point of interest is that no-reflow phenomenon was not observed in any of the lesions with direct implantation, despite the presence of thrombus in $65 \%$ of these lesions. This could be explained by the covered vessel area provided by the Absorb, which has a footprint that doubles that of metallic stents (26\% in Absorb vs. $12 \%$ in Xience). This could enhance the possibility to trap thrombus and thereby to reduce the risk of no-reflow phenomenon. However, an important issue in this setting is the correct selection of the stent diameter. In the absence of intracoronary image guidance, the diameter could be underestimated due to the vasoconstriction and presence of thrombus. This could favour incomplete scaffold apposition and be a potential niche for thrombosis.

The use of direct implantation in a different clinical scenario should be avoided, especially in the absence of intracoronary imaging guidance. In ACS the plaque is soft, therefore it is easy to cross the lesion, and the strut is embedded in the plaque, favouring vascular healing. Furthermore, as revealed in the study of Rzeszutko et al. [9], correct expansion of the platform is obtained, minimising the possibility of scaffold thrombosis. However, in stable patients, lesions have fibrocalcic plaques that may prevent correct expansion of the platform despite an aggressive postdilation. In the CORPAL registry with Absorb [10] we included 569 lesions treated with direct implantation, 367 in the setting of ACS, and 202 in stable patients. After a mean follow-up of 29 months, the rate of scaffold thrombosis in patients with ACS was $0.87 \%$, while in stable patients it was $4 \%$. The high thrombosis rate could be explained by the inability to obtain a proper expansion. In addition, in this context, we probably induced double stress to the platform (first expanding the platform against a hard plaque and then performing a more aggressive postdilation), which could have weakened its radial force. Furthermore, it was recently suggested that an eccentric expansion could alter the laminar flow, favouring the development of thrombosis, and that a circular expansion can only be ensured with an aggressive predilation in fibrotic plaques [11]. 
Therefore, based on direct BVS implant studies [7-9] in the setting of ACS, we can conclude that it is a feasible technique with excellent immediate results. However, it is necessary to confirm whether or not this technique has a negative impact in the long term.

\section{Conflict of interest: none declared}

\section{References}

1. Serruys PW, Ormiston JA, Onuma Y, et al. A bioabsorbable everolimus-eluting coronary stent system (ABSORB): 2-year outcomes and results from multiple imaging methods. Lancet. 2009; 373(9667): 897-910, doi: 10.1016/S0140-6736(09)60325-1, indexed in Pubmed: 19286089.

2. Onuma Y, Serruys PW, Ormiston JA, et al. Three-year results of clinical follow-up after a bioresorbable everolimus-eluting scaffold in patients with de novo coronary artery disease: the ABSORB trial. EuroIntervention. 2010; 6(4): 447-453, doi: 10.4244/EIJ30V6I4A76, indexed in Pubmed: 20884431.

3. Simsek C, Karanasos A, Magro M, et al. Long-term invasive follow-up of the everolimus-eluting bioresorbable vascular scaffold: five-year results of multiple invasive imaging modalities. EuroIntervention. 2016; 11(9): 996-1003, doi: 10.4244/EIJY14M10 12, indexed in Pubmed: 25349042.

4. Ellis SG, Kereiakes DJ, Metzger DC, et al. Everolimus-eluting bioresorbable scaffolds for coronary artery disease. N Engl J Med. 2015; 373(20): 1905-1915, doi: 10.1056/NEJMoa1509038, indexed in Pubmed: 26457558.

5. Wykrzykowska JJ, Kraak RP, Hofma SH, et al. AIDA Investigators. Bioresorbable Scaffolds versus Metallic Stents in Routine
PCI. N Engl J Med. 2017; 376(24): 2319-2328, doi: 10.1056/NEJMoa1614954, indexed in Pubmed: 28402237.

6. Puricel S, Cuculi F, Weissner M, et al. Bioresorbable coronary scaffold thrombosis: multicenter comprehensive analysis of clinical presentation, mechanisms, and predictors. J Am Coll Cardiol. 2016; 67(8): 921-931, doi: 10.1016/j.jacc.2015.12.019, indexed in Pubmed: 26916481.

7. Suárez de Lezo J, Martín P, Mazuelos F, et al. Direct bioresorbable vascular scaffold implantation: Feasibility and midterm results. Catheter Cardiovasc Interv. 2016; 87(5): E173-E182, doi: 10.1002/ccd.26133, indexed in Pubmed: 26268440.

8. Sabaté M, Windecker S, Iñiguez A, et al. Everolimus-eluting bioresorbable stent vs. durable polymer everolimus-eluting metallic stent in patients with ST-segment elevation myocardial infarction: results of the randomized ABSORB ST-segment elevation myocardial infarction-TROFI II trial. Eur Heart J. 2016; 37(3): 229-240, doi: 10.1093/eurheartj/ehv500, indexed in Pubmed: 26405232.

9. Rzeszutko Ł, Węgiel M, Kleczyński P, et al. Direct Absorb bioresorbable scaffold implantation in acute coronary syndrome. Kardiol Pol. 2018; 76(10): 1434-1440, doi: 10.5603/KP.a2018. 0147.

10. Serruys PW, Katsikis A, Onuma Y. Long-term data of BRS presented at EuroPCR 2017 (Friday, 19 May). EuroIntervention. 2017; 13(5): e515-e521, doi: 10.4244/EIJV13I5A82, indexed in Pubmed: 28781248.

11. Serruys PW, Onuma Y. Dmax for sizing, PSP-1, PSP-2, PSP-3 or OCT guidance: interventionalist's jargon or indispensable implantation techniques for short- and long-term outcomes of Absorb BRS? EuroIntervention. 2017; 12(17): 2047-2056, doi: 10.4244/EIJY17M02_01, indexed in Pubmed: 28246059 . 